\title{
The Role of Networks and Planning, in the Improvement of Impaired Waters in Urbanizing Counties within North Carolina
}

\author{
Kurt W. Smith \\ Environmental Management, Methodist University, Fayetteville, US \\ Email: kusmith@methodist.edu
}

Received 12 October 2014; revised 17 November; accepted 8 December 2014

Copyright (C) 2014 by author and OALib.

This work is licensed under the Creative Commons Attribution International License (CC BY).

http://creativecommons.org/licenses/by/4.0/

(c) (i) Open Access

\section{Abstract}

The state of North Carolina continues to grow at a rapid rate. The rise of negatively impacted streams, particularly within urbanizing counties, continues to expand. Considerable effort and public funding are spent through a variety of agencies that attempt to deal with the problem on a collaborative basis through management networks. A study using surveys, a plan quality rating tool and the U.S. Environmental Protection Agency (EPA) list of impaired (303d) streams was conducted to determine the strength of these networks, the quality of the plans they produce, and finally if those plans lead to improved water quality. Several areas, identified based on the data, suggest improvements in the functioning of networks and planning efforts directed toward water quality improvement.

\section{Keywords}

Management Networks, Sustainable Water Quality Improvement, Urbanizing Watersheds

Subject Areas: Environmental Sciences, Hydrology

\section{Introduction}

Watershed management is not a new idea. It was first proposed in the United States by John Powell in the 1880s, as he envisioned organizing and governing according to watershed boundaries rather than political boundaries in the expanding west (e.g. McGinnis, Wooley, Gamman [1]). Powell was in many ways ahead of his time in thinking about the best way to conduct watershed management. 
Networks are simply defined as a group of people or organizations that are closely connected and that work with each other (network, 2014. In Merriam-Webster.com retrieved November $18^{\text {th }} 2014$ from

http://www.merriam-webster.com/dictionary/network [2]). In the case of watersheds it has become impossible to work in any other way, except through the network. By simply understanding that no single organization of government can achieve its policy intentions alone, and that it requires the work of multiple actors, all with significant capabilities to manage the flow of problems and solutions into policy action (e.g. Bressers [3]), a great deal can be achieved. These programs that facilitate a policy intention are often spread out across federal, state, local government, and non-government orginazations, which reflect varying degrees of capacity and innovation (e.g. Elazar [4]), (e.g. Ostrom [5]), (e.g. Wright [6]). The network managed well possesses the capacity to move multiple agencies and programs with divergent goals and capacities towards a collective benefit and improved efficiency with scarce public resources, that otherwise could not be realized. The goal then for public managers, is to find ways to improve governance within these complex networks with multiple actors, which are incapable of accomplishing their mission acting alone (e.g. Provan and Milward [7]).

Understanding a network, how it operates in its strengths, weaknesses, and its effectiveness at protecting and improving water quality is an important endeavor. One of the primary products of a network is a plan. Plans are defined as a set of actions that have been thought of as a way to do or achieve something (plan, 2014. In Merriam-Webster.com retrieved November $18^{\text {th }} 2014$ from http://www.merriam-webster.com/dictionary/plan [2]).

There is also a necessity to understand the quality, purpose and outcomes of the plans these networks produce, and what these plans actually accomplish. Plans are the clearest signal of intention and agreement within a network. How well these plans are carried out should tell us something about the effectiveness of the networks, and ultimately say something about what is being accomplished and what is not in order to better protect and improve water quality in North Carolina's urbanizing areas.

\section{The Architecture of U.S. Water Quality Networks}

The Clean Water Act provides much of the architecture upon which watershed management networks are built. States must develop lists (303d) of waters not meeting requirements of their classified purpose (recreation, drinking water). From these lists TMDLs, or Total Maximum Daily Loads, are produced. The TMDL calculates the maximum amount of a pollutant allowed to enter a waterbody, also known as the loading capacity, so that the waterbody will meet and continue to meet water quality standards for that particular pollutant. Meeting the TMDL then becomes the responsibility of state, and local government in partnership with federal agencies, thus creating the need for combined collaborative planning. In fact, knowledge of local situations and the coordination of multiple agencies is difficult to accomplish without the development and engagement of a collaborative network (e.g. Sabatier [8]). There is little data available to indicate if these networks and their corresponding plans are effective in protecting and improving water quality as they operate throughout North Carolina. This should be a concern and of interest for those who work in government in that they are held accountable for public funds and meeting public purposes efficiently (e.g. Provan and Milward [7]).

\section{Literature Review}

Competition for water resources from agriculture, industrial users, development, recreationists, fisheries as well as requirements from the Clean Water Act have created a general era of dissatisfaction with the management of these resources (e.g. Sabatier, Focht, Lubell, Trachtenburg, Vedlitz, Matlock [8]). From this has sprung a new collaborative watershed approach which have some common features: 1) They use a hydrographic boundary as opposed to political boundaries; 2) They involve a wide array of stakeholders from multiple agencies and multiple levels of government and the community; 3) negotiations occur in face to face interactions among participants; 4) the goal of the process is to find win-win solutions among economic, scientific and social interests; 5) the process uses an extensive fact finding effort which typically blends scientific knowledge with local expertise (e.g. Sabatier et al. [8]).

Many jurisdictions have developed collaborative rules aimed at nitrogen reduction within the watershed. This has created an urgent need to look both at agricultural practices as well as development practices in the basin. One challenge is quantifying reductions after implementation of plans is that any reductions in-stream will likely not be detected for at least four to five years after improvements are made in loading (e.g. Stow et al. [9]). Collaborative efforts have also been undertaken to protect the buffers to streams. These riparian areas and its vege- 
tation help control the transport of sediments and chemicals into stream channels. They can serve as both a short and long-term filter and are invaluable (e.g. Lawrance [10]).

Urbanizing counties in North Carolina have challenges stemming from development, but most have a substantial agricultural influence in areas surrounding the urban and suburban core. Conventional farming consists of plowing, disking and harrowing which creates erodible soil impacting water quality. New conservation cropping techniques and no till planting have created great opportunities to improve water quality when applied across the watershed (e.g. Endale et al. [11]).

The term "network" has become synonymous with the term organizational complexity. One article characterizes networks by saying the networks have a set of stable relationships that is non-hierarchal, interdependent of each other, and links a variety of actors. These actors and groups at their core have interest in sharing resources and information in order to advance towards common goals (e.g. Borzell [12]). As such, these networks organize not according to hierarchy, but according to needs which are linked together to share resources and achieve common goals. Network theory is a helpful model for thinking about how we are managing our watersheds.

After an extensive literature review, Michael McGuire (2006), concludes there are four things we know about managing collaboratively through networks: 1) That collaborative management is a component of public management that is here to stay; 2) More work needs to be done through research on the types of skills needed to be effective in network settings; 3 ) There is renewed interest in finding out more about the effect of collaboration on program outcomes; 4) There is still much to learn about managing collaboratively through the network, and the questions left to be answered are nearly endless (e.g. McGuire [13]).

Networks are also charged with the task of implementing. Implementation within a geo-political watershed network creates a number of challenges for the public manager. The more decision points, that go into implementing the more likely it is the outcome is going to fail (e.g. Pressman and Wildavsky [14]). It may be the case that watershed collaborative networks have embedded within them great problems of achieving their goals regarding implementation.

Some networks exist and cease to exist over mandates, interpersonal friendships, and proximity, individual or collective action. The use of Network Theory that understands the how and when interactions come into being may be more useful then understanding the mechanics of networks in seeing how collective action happens (e.g. Salancik [15]).

Plans are only important for the practitioner to recognize that planning and plans are a process of conversation, an aggregation of thoughts and preferences. How well this takes place is much more art than science and may well dictate the ability of a plan to articulate policy and intentions and implementation (e.g. Hopkins [16]).

\section{The Research Model}

Figure 1 illustrates the basic premise of my research. Strong networks, are networks that collaborate, have mutual goals, communicate, plan and engage in work together. They produce plans together across jurisdictional bounds and across interests, they share expertise and resources and produce ideas which are concrete and intentional at producing uplift within the watersheds. These intentions are codified and agreed upon in plans. When implemented, these plans in turn, should produce positive and measurable effects in the watershed.

To assist in this study a set of tools were developed to measure network strength, plan quality, and water quality improvement and to see if links exist between these three activities. Effort was made to identify specific weaknesses or strengths which can be refined, exploited, or improved to benefit of improving and protecting important water resources.

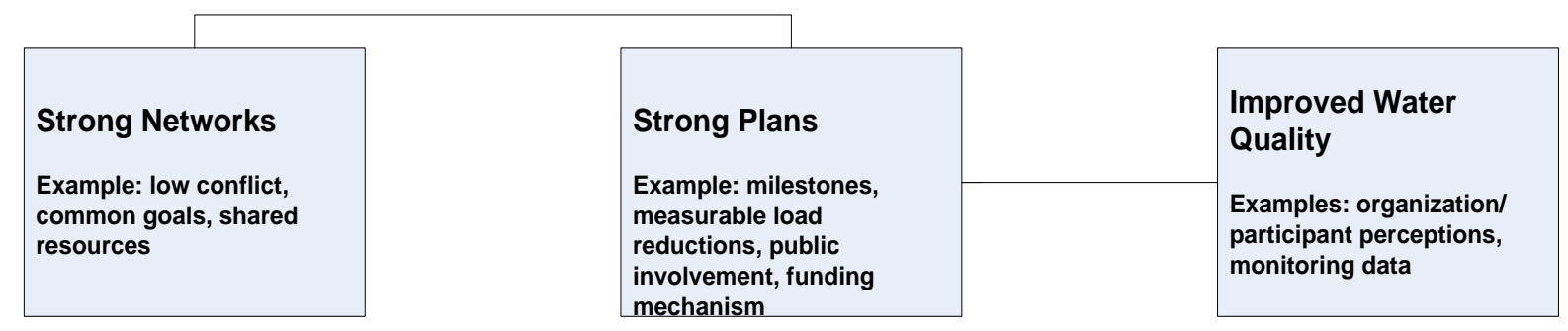

Figure 1. Study model. 


\section{The Tools Developed}

A survey instrument was developed, designed and administered to extract information in one primary area, that of network strength. A couple of extra questions were added in to test respondent perceptions on the quality of plans they produce, and their overall perception of water quality in North Carolina Counties. Eighty-eight surveys were sent out to watershed management professionals working in each of the counties. Fifty-eight responses were received back for a response rate of $65 \%$.

A second instrument, a plan evaluation tool was developed resting largely on the work of Phillip Berke, which measured plan quality. Plan quality was evaluated by three individual raters, with expertise in watershed issues and planning, for each of four counties (Wake, Mecklenburg, Forsyth and Guilford counties). Plans were examined of three types: stormwater plans, comprehensive land use plans and watershed plans. The major characteristics of good plans are: issue identification, goals, fact based, policies, implementation, monitoring and evaluation, internal consistency, organization and presentation, inter-organizational coordination, and compliance (e.g. Berke, Godschalk, and Kaiser [17]). The tool allows us to measure the quality of plans produced by each of the four networks, through an empirically validated methodology applied specifically to our four urbanizing counties.

A third and final tool was developed through the compilation of the rate of increase in 303d listed waters from 2006-2010, coupled with the rate of population increase for the same period. This was used as a proxy for quantifying water quality improvement for each county along with watershed professional's perceptions of water quality improvement through a survey question. The data used is collected in an equal percentage by county, in North Carolina, every two years. Collectively these increases evidenced in the data should be viewed more directionally as a view to water quality supported by science then as a precise accounting of water quality in each county.

\section{Results}

\subsection{Network Strength}

A survey was administered via the web and quantified network strength based on perceptions of watershed management professionals actively working in all four of the urbanizing counties. The primary measure of strength were the presence of strong water quality goals, the belief in and amount of collaborative activities, and the amount and type of conflict at work within the networks. The survey results indicated that 95\% of respondents believed their organization held strong or very strong water quality goals. When examining respondents views towards collaboration, 93\% believed in the value of collaborating to get their work done. Interestingly $63 \%$ felt that the amount of collaboration going on within the network was weak or very weak. Finally $41 \%$ acknowledged that conflict existed within the network, but characterized this conflict as being weak and infrequent. These findings indicate that more can be done to expand collaboration among network participants. The relative absence of conflict is also consistent with the lack of collaborating going on in the networks. The good news in the survey on network strength is that there seems to be strong goal alignment around water quality improvement and protection as a unifying goal among all respondents.

\subsection{Plan Quality Evaluation Data}

The plan evaluation tool examined three types of plans related to water quality improvement and protection in each county. The attributes which rated the plan quality were: issue identification, goals, fact based, policies, implementation, monitoring and evaluation, internal consistency, organization and presentation, inter-organizational coordination, and compliance. Table 1 combines the attribute scores by county and plan type and assigns an overall grade of excellent, very good, good, fair, and poor. Table 1 shows the average score of each plan type by county, and then rated on a 100 point scale. A score less than 60 received a grade of poor.

This table shows us that overall watershed plans are rated as good, stormwater plans as poor, and comprehensive plans as good. Combining the scores for all counties and all pans types planning efforts receive a grade of fair or 68.57. In short, there is empirical evidence that there is room for improvement in planning efforts within the networks in all of the studied counties.

When comparing perceptions of plans by survey respondents to the independently evaluated plan ratings, $72 \%$ of survey respondents viewed plans as being either good or very good. This perception is slightly more optimis- 
tic than the assessment of plans by individual raters of the plans using the plan evaluation tool.

\subsection{Water Quality Data Indicators}

Table 2 shows the total miles of stream within each county, and the percentage of counties total stream miles that were listed as impaired in 2006 and in 2010. It also indicates in the bottom row the total percentage increase by county over that four year period. It also shows population by county in 2006 and 2010 and the percentage of increase over that period.

\section{Conclusions}

All respondents reported that their organization engaged in collaborative activity. All respondents also reported their organization had increase capacity to collaborate more than they now do. Ninety-seven percent viewed the attainment of agency goals as being enhanced through collaboration with other agencies. Notable from this data is that for all counties combined population has increased over the four-year period by $9.5 \%$ while $303 \mathrm{~d}$ listed streams have increased over the same period by $150 \%$. Undoubtedly things would be much worse without the efforts of the networks, but it is apparent that the stress on watersheds is far outpacing what the networks can do though planning an implementation. The data would suggest combined efforts from local, state and federal sources aimed at protecting the environment are insufficient. It suggests that the impacts may reach beyond anything the current network structure can do to address the problem. When respondents to the survey were asked about their perceptions of water quality improvement within the county, $77 \%$ believed that water quality in the county had either improved or slightly improved, while 19\% observed no change. This perception seems significantly optimistic in the continued growth of streams being listed as impaired within each county.

The research indicates that the networks have strength in well aligned goals, but collaboration is underutilized within the networks. Collaboration occurs primarily around necessity or where skills are complimentary. The networks need to increase their efforts at collaborating and working together on a more routine basis.

When contrasting the perceptions of water quality professionals with the independent evaluations of plans by raters using the empirically validated assessment tool, rated plans received a less favorable assessment and were

Table 1. Plan evaluation scores.

\begin{tabular}{ccccc}
\hline County/Plan Type & Local WS Plan & Stormwater Plan & Comprehensive Plan & Overall Grade \\
\hline Wake & 83.3 & 91.6 & 63.3 Very Good & 67.5 \\
Mecklenburg & 83 & 62.3 & 67.93 Good & 77.6 \\
Forsyth & 28.3 & 67.6 & 54.3 & 56.23 Poor \\
Guilford & 86.3 & 62.4 Fair & 73.1 Good \\
\hline
\end{tabular}

Table 2. Impaired streams and populations.

\begin{tabular}{|c|c|c|c|c|c|}
\hline & Wake & Forsyth & Guilford & Mecklenburg & All Counties \\
\hline Total stream miles & 998 & 413 & 689 & 556 & 2656 \\
\hline \% of 303d listed 2006 & 43.70 miles $4 \%$ & 14.08 miles $3 \%$ & 41.60 miles $5 \%$ & 69.62 miles $12 \%$ & 169 miles $6 \%$ \\
\hline 2006 population & 792,940 & 332,355 & 451,905 & 827,445 & $2,404,645$ \\
\hline$\%$ of 303d listed 2010 & 139.30 miles $13 \%$ & 43.63 miles $11 \%$ & 72.71 miles $10 \%$ & 162.16 miles $29 \%$ & 417.8 miles $15 \%$ \\
\hline 2010 population & 900,993 & 350,670 & 488,406 & 919,000 & $2,659,069$ \\
\hline $\begin{array}{c}\text { \% increase 303d listed } \\
\text { 2006-2010 }\end{array}$ & $225 \%$ & $266 \%$ & $100 \%$ & $141 \%$ & $150 \%$ \\
\hline$\%$ of increase population & $11.9 \%$ & $5.2 \%$ & $7.47 \%$ & $9.9 \%$ & $9.5 \%$ \\
\hline
\end{tabular}


found to be lacking in two areas consistently: implementation and participation. This would suggest that these are two areas of concern and improvement for the manager of water resources. While more research is needed, it may provide a causal link for why these plans produce limited results in stemming the growing miles of impaired streams in North Carolina's urbanizing counties.

The growing list of 303d listed streams, and the shrinking size of budgets all point to the value and saliency of additional research, thought and consideration of the way in which watershed management networks collaborate, plan and implement. This research suggests the need for greater collaboration and implementation of practices which make a difference in the streams of urbanizing areas. More study should be undertaken to ensure that public managers have the requisite skill sets to manage networks effectively. Public managers will need to expand their skill sets beyond the technical and have acumen for developing the interpersonal skills for managing many dimensions of human interaction and associated processes, and to better quantify the effectiveness of network efforts at improving water quality. More effort should be undertaken to integrate dimensions of sustainability and the precautionary principal as an organizing cornerstone for the networks plans, implementation, and improving our all-important water resources.

\section{References}

[1] McGinnis, M.V., Wooley, J. and Gamman, J. (1999) Bioregional Conflict Resolution: Rebuilding Community in Watershed Planning and Organizing. Environmental Management, 24, 1-12. http://dx.doi.org/10.1007/s002679900210

[2] (2014) Merriam-Webster.com. http://www.merriam-webster.com/dictionary

[3] Bressers, H., O’Toole Jr., L.J., and Richardson, J. (1995) Networks as Models of Analysis: Water Policy in Comparative Perspective. In: Bressers, H., O’Toole, Jr., L.J. and Richardson, J., Eds., Networks for Water Policy: A Comparative Perspective, Frank Cass, London, 1-23.

[4] Elazar, D. (1987) Exploring Federalism. University of Alabama Press, Tuscaloosa.

[5] Ostrom, E. (1990) Governing the Commons: The Evolution of Institutions for Collective Action. Cambridge University Press, New York. http://dx.doi.org/10.1017/CBO9780511807763

[6] Wright, D.S. (1988) Understanding Intergovernmental Relations. 3rd Edition, Brooks/Cole, Pacific Grove.

[7] Provan, K.G. and Milward, H.B. (2001) Do Networks Really Work? A Framework for Evaluating Public-Sector Organizational Networks. Public Administration Review, 61, 414-423.

[8] Sabatier, P.A., Focht, W., Lubell, M., Trachtenberg, Z., Vedlitz, A. and Matlock, M. (2005) Swimming Upstream: Collaborative Approaches to Watershed Management. MIT Press, Cambridge.

[9] Stowe, C.A., Borusk, M.E. and Stanley, D. (2001) Long-Term Changes in Watershed Nutrient Inputs and Riverine Exports in the Neuse River, North Carolina. Water Research, 35, 1489-1499. http://dx.doi.org/10.1016/S0043-1354(00)00402-4

[10] Lawrance, R., Todd, R., Fail Jr., J., Hendrickson Jr., O., Leonard, R. and Asmussen, L. (1984) Riparian Forests as Nutrient Filters in Agricultural Watersheds. BioScience, 34, 374-377. http://dx.doi.org/10.2307/1309729

[11] Endale, D.M., Schomberg, H.H. and Steiner, J. (2000) Long-Term Sediment Yield and Mitigation in a Small Southern Piedmont Watershed. International Journal of Sediment Research, 14, 60-68.

[12] Borzel, T.A. (1998) Organizing Babylon-On the Different Conceptions of Policy Networks. Public Administration, 76, 253-273.

[13] McGuire, M. (2006) Collaborative Public Management: Assessing What We Know and How We Know It. Public Administration Review, 66, 33-43.

[14] Pressman, J. and Wildavsky, A. (1984) Implementation, the Oakland Project. University of California Press, Oakland.

[15] Salancik, G. (1995) Wanted: A Good Network Theory of Organization. Administrative Science Quarterly, 40, 345-349. http://dx.doi.org/10.2307/2393642

[16] Hopkins, L.D. (2001) Urban Development: The Logic of Making Plans. Island Press, Washington, D.C.

[17] Berke, P.R. and Conroy, M.M. (2000) Are We Planning for Sustainable Development? An Evaluation of 30 Comprehensive Plans. Journal of the American Planning Association, 66, 21-33. http://dx.doi.org/10.1080/01944360008976081 